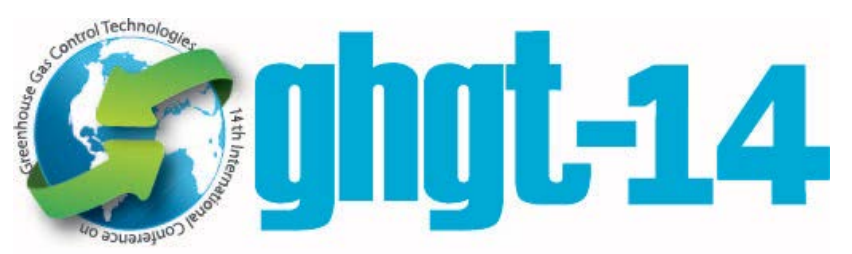

14th International Conference on Greenhouse Gas Control Technologies, GHGT-14

$21^{\text {st }}-25^{\text {th }}$ October 2018, Melbourne, Australia

\title{
Ensuring efficient and robust offshore storage - the role of marine system modelling.
}

\author{
Jerry Blackford ${ }^{\mathrm{a}}{ }^{*}$, Guttorm Alendal ${ }^{\mathrm{b}}$, Yuri Artioli ${ }^{\mathrm{a}}$, Helge Avlesen ${ }^{\mathrm{c}}$, Pierre W. \\ Cazenave $^{\mathrm{a}}$, Baixin Chen ${ }^{\mathrm{d}}$, Andrew W. Dale ${ }^{\mathrm{e}}$, Marius Dewar ${ }^{\mathrm{d}}$, Maribel I. García-Ibáñez ${ }^{\mathrm{c}}$, \\ Jonas Gros ${ }^{\mathrm{e}}$, Kristian Gundersen ${ }^{\mathrm{b}}$, Matthias Haeckel ${ }^{\mathrm{e}}$, Sorush Khajepor ${ }^{\mathrm{d}}$, Gennadi \\ Lessin $^{\mathrm{a}}$, Anna Oleynik ${ }^{\mathrm{b}}$, Abdirahman M. Omar ${ }^{\mathrm{c}}$, Umer Saleem ${ }^{\mathrm{d}}$. \\ ${ }^{a}$ Plymouth Marine Laboratory, Prospect Place, Plymouth, PL1 3DH, UK \\ ${ }^{b}$ Department of Mathematics, University of Bergen, Bergen, Norway \\ ${ }^{c}$ Uni Research Climate, Bjerknes Centre for Climate Research, Bergen 5008, Norway \\ ${ }^{d}$ Institute of Mechanical, Process and Energy Engineering, Heriot-Watt University, Edinburgh, EH14 4AS, UK \\ ${ }^{\mathrm{e}}$ GEOMAR Helmholtz Centre for Ocean Research Kiel, Wischhofstrasse 1-3, 24148 Kiel, Germany
}

\begin{abstract}
This paper describes the utility of developing marine system models to aid the efficient and regulatory compliant development of offshore carbon storage, maximising containment assurance by well-planned monitoring strategies. Using examples from several model systems, we show that marine models allow us to characterize the chemical perturbations arising from hypothetical release scenarios whilst concurrently quantifying the natural variability of the system with respect to the same chemical signatures. Consequently models can identify a range of potential leakage anomaly detection criteria, identifying the most sensitive discriminators applicable to a given site or season. Further, using models as in-silico testbeds we can devise the most cost-efficient deployment of sensors to maximise detection of $\mathrm{CO}_{2}$ leakage. Modelling studies can also contribute to the required risk assessments, by quantifying potential impact from hypothetical release scenarios. Finally, given this demonstrable potential we discuss the challenges to ensuring model systems are available, fit for purpose and transferable to CCS operations across the globe.

Keywords: CCS; Offshore; Storage; Marine; Monitoring; Modelling
\end{abstract}

\section{Introduction}

Offshore geological storage options are available in many countries; however demonstrating robust storage poses some unique challenges in the marine environment. To comply with regulations and assure against false accusations, traditional seismic imaging of the storage complex and overburden can be complemented by monitoring at the sea floor for biochemical or physical anomalies, such as excess $\mathrm{CO}_{2}$ concentrations or gas bubbles. Sea-floor techniques

* Corresponding author. Tel.: +44 (0)1752633462; fax: +44 (0)1752 633101.
E-mail address: jcb@pml.ac.uk 
may have better sensitivity than seismics and contribute to all parts of the detection-location-verificationquantification process. Outstanding challenges include defining what constitutes an anomaly in a noisy time variant environment, and identifying optimal sensor combinations and deployment strategies to provide a sensitive, wideranging, accurate yet economic monitoring system. Here we demonstrate how marine modelling approaches are answering these challenges.

Developing a monitoring system requires that we meticulously understand the signals of leakage, and how these differ from natural, often highly-dynamic variability. For example, we need to predict the pathways of $\mathrm{CO}_{2}$ transfer across the sediment-water interface, its phase chemistry under a variety of environmental conditions, the configuration of gas bubbles, their displacement and aqueous dissolution, the movement and dispersion of dissolved $\mathrm{CO}_{2}$ plumes and their impact on the marine chemistry. In addition, we need to characterise how the same chemical and physical attributes evolve due to natural biological and physical processes. Understanding such "baselines", perhaps better termed natural variability, which will always be site- and season-specific, is critical to facilitate the successful detection and quantification of unintended emissions, for the application of corrective actions as well as the protection from false alarms.

Marine observations are generally expensive to undertake, requiring boat based surveys or the deployment of autonomous underway or fixed platforms. For scientific and practical reasons observations are biased towards the surface ocean and periods of poor weather are under-sampled. Consequently, sea floor marine systems are poorly described by direct observations, and the data that is available tends to be intermittent and sparse. However coastal regions are routinely described by marine system models - typically time evolving, 3D coupled hydrodynamicbiogeochemical systems which describe physical flows and biogeochemical fluxes, often explicitly modelling $\mathrm{CO}_{2}$ chemistry (aka carbonate chemistry) and potentially hosting specialist modules, for example of bubble dynamics. Such models are run as decadal scale hind-casts and for short-term operational forecasts, both modes often using assimilation of observations to improve accuracy [1]. Models are also run in long-term climate forecast mode which allows for the assessment of impacts of increased atmospheric $\mathrm{CO}_{2}$ emissions and other anthropogenic factors [2]. These models provide terabytes of internally-consistent, evaluated, skill-assessed [3] multi-variate data with comprehensive vertical, horizontal and temporal resolution - a virtual marine environment within which we can quantify baselines, simulate unplanned release and assess monitoring strategies.

\section{Model developments and outcomes}

Within a number of past and ongoing research and development projects, including STEMM-CCS [4], BayMoDe [5] and ECO2 $[6,7,8,9]$ the research community has devoted considerable effort to developing and applying marine system models to advance offshore storage. We can now articulate the following understanding, advances and tools that will facilitate the development of geological storage in the marine domain.

\subsection{Characterization of hypothetical release scenarios}

In the absence of sufficient realistic analogues, models provide the only option to characterize the morphology of diverse hypothetical release events via sediments and water column (Fig 1), and thereby quantify detection targets. Offshore analogues of $\mathrm{CO}_{2}$ release (natural seeps) do exist and can be helpful in establishing broad scale understanding of phenomena, however these are substantially variant from a CCS scenario. For example methane seeps, often biogenic in nature, are common, but methane has distinctly different solubility characteristics in seawater compared to $\mathrm{CO}_{2}$ [10]. $\mathrm{CO}_{2}$ seeps are also found in the marine environment, but often associated with volcanic activity, such that their location and environmental characteristics are not a close match with existing and potential storage sites. Controlled deliberate injection/release experiments are expensive and therefore rare [11] and whilst informative [12] deliver limited scenario variability.

A number of studies have used combinations of sediment, hydrodynamic and biogeochemical models to 
characterise a wide variety of "leakage" scenarios. The primary varient between these studies is the spatial model resolution and the release rate tested. A-priori information on potential leak scenarios is by definition scant as the only expected scenario is no release. Consequently modelled scenarios range from the smallest rates that could be sensibly resolved by a particular model system to upper limits defined by injection rates, or especially in early research even more extreme releases, designed to demonstrate certain environmental consequences rather than be constrained by the operational reality of storage. Typically operational shelf models have resolutions of the order of $10 \mathrm{~km}$ in the horizontal, which are only suitable to represent dissolved phase plumes with footprints an order of magnitude larger [13]. However shelf scale models with resolutions approaching $1 \mathrm{~km}$ [14] have been applied as have sub-regional model domains whose resolution can be as fine as $1 \mathrm{~m}[15,16]$, which allow very small release rates to be tested. These ultra-high resolution models also allow multiphase simulations, including the dynamics of bubble plumes as well as the dissolved phase [17]. Models of the upper layers of unconsolidated sediments [18] further enable the characterisation of multiphase flow and inform the morphology of leakage, in particular the nature of flow across the sediment-water interface which can modify the distribution of $\mathrm{CO}_{2}$ plumes in the vicinity of the release point(s) and crucially affects the initial plume height with implications for broader scale dispersion and outgassing to the atmosphere as well as the visibility of gas bubble plumes to acoustic detection.
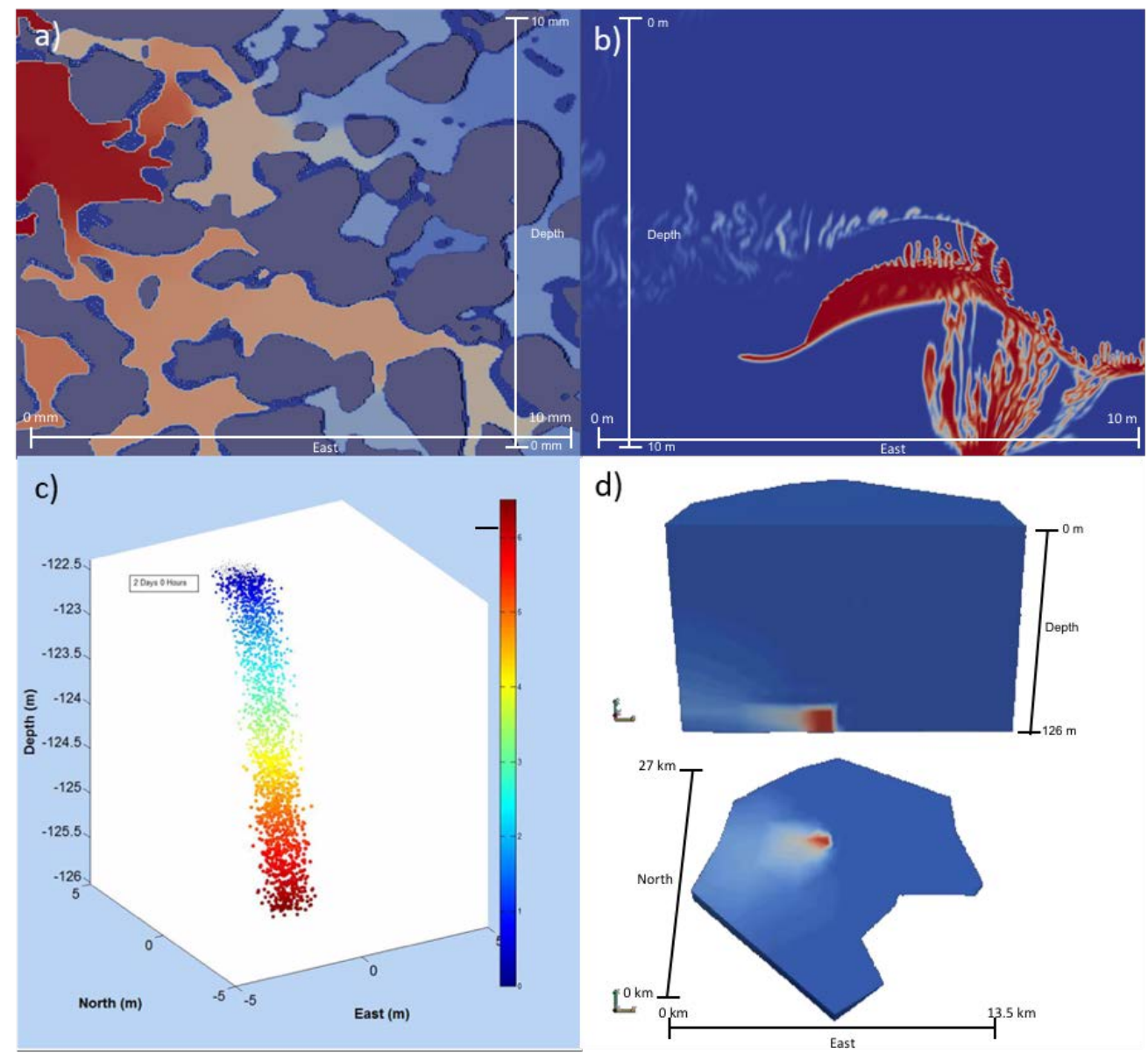

d)
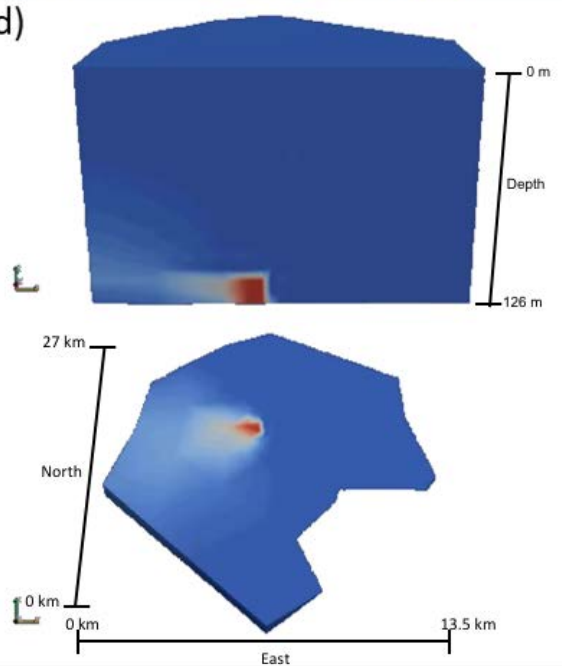

Figure 1. a) Flow through porous media in the pore scale (by a Lattice Boltzmann model, shown in terms of fluid pressures); b) Flow through porous media (red) and into the water column (white) in the meter scale (by a Navier-Stokes Darcy model shown in terms of void fraction); c) $\mathrm{CO}_{2}$ bubble plumes rising and dissolving in the water column (by a multiphase plume model shown in terms of bubble size - mm); d) flow of dissolved $\mathrm{CO}_{2}$ solution in the water column (by a multiphase plume model shown in terms of dissolved mass concentration). 
As a result of this combined body of work we have a growing set of quantified release scenarios, ranging over at least seven orders of magnitude (see Fig 5). Primarily plume size (and therefore impact and detectability) relates to release rate according to a power law, consistent with the general dispersion of substances in marine environments [19]. However very significant variability of plume morphology is driven by the spatially and temporally varying tidal mixing vectors and seasonal weather-related phenomenon such as the degree of stratification and wind-induced mixing. Plumes are highly dynamic in space and time, often circulating around a release point on a tidal ellipse, with the strength of the perturbation decreasing with distance from the release point (Fig 1d).

\subsection{Understanding and quantifying natural variability}

Natural variability of marine $\mathrm{CO}_{2}$ (Fig 2) may mask the signal from an unplanned release, and can also help to define the unperturbed state should an environmental impact assessment be necessary. Observational studies have demonstrated that the degree of variability itself varies according to location and season and is driven by a complex range of factors, which may include advection of water masses of different origin, influence of nearby riverine plumes, atmospheric $\mathrm{CO}_{2}$, temperature, biological activity and in-situ mixing [20]. Conducting a comprehensive survey of the carbonate system to characterize the diurnal-seasonal-inter-annual and spatial variability of a particular storage site could be prohibitively expensive. However coupled model systems, which include sufficient process definition enable us to predict, extrapolate and quantify natural variability and its heterogeneity. A sufficient model system should include fully 3-dimensional hydrodynamics, riverine inputs, exchanges with open ocean boundaries and the atmospheric system, representation of biogeochemical processes especially community respiration and primary production and a fully resolved implementation of carbonate chemistry [21].
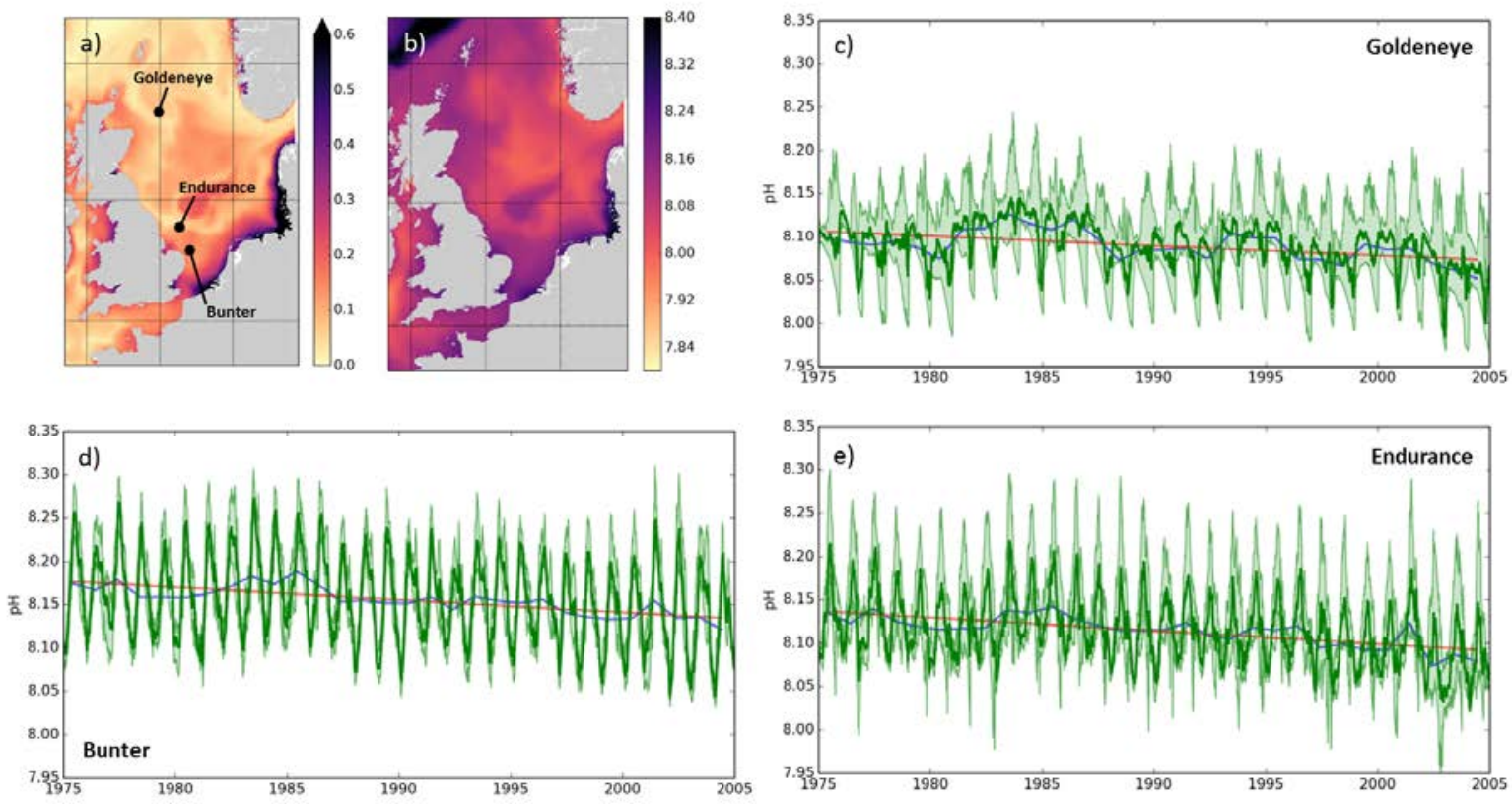

Figure 2. a) Annual range of seafloor $\mathrm{pH}$ (indicating $\mathrm{CO}_{2}$ concentration) in the North Sea and b) mean pH using the NEMO-ERSEM model; c-e) contrasting evolution of baseline chemistry at different North Sea sites extracted from the model. Green shading shows the local variability, lines: green - daily mean, blue - annual mean, orange - acidification trend.

The example shown in figure 2 illustrates that within one regional sea, there are very distinct short-term, seasonal and inter-annual $\mathrm{CO}_{2}$ dynamics, here using $\mathrm{pH}$ as a measure of concentration of $\mathrm{CO}_{2}$. The annual range of $\mathrm{pH}$ varies between $0.5 \mathrm{pH}$ units or more in shallow near shore environments where riverine influences are high, as are productivity cycles, to $0.1 \mathrm{pH}$ units in deeper more oceanic conditions, where external influences and productivity 
are minimized. Variability in shallow coastal regions tends to be dominated by seasonality whilst offshore, interannual variability and climate oscillations tend to be more influential. Only the long-term trend associated with ocean acidification is relatively constant across the region as this is a broad scale phenomenon driven by atmospheric $\mathrm{CO}_{2}$ concentrations. On sub-diurnal timescales variability is driven by a combination of tidal mixing and the light-dark cycle of production/respiration. In the same region, changes within 24-hour periods are predicted to be of the order of 0.01-0.05 pH units, with maxima associated with peak biological and physical events [22].

\subsection{Defining anomaly criteria}

Perturbations arising from a release may be small, and of a similar magnitude to natural changes in $\mathrm{CO}_{2}$ concentration especially if monitored at some distance from a release point. The challenge therefore is to develop highly sensitive criteria that identify anomalous chemistry as distinct from natural dynamics, minimizing the chance for false positives. By combining models of release scenarios and natural variability we can use these models to identify optimal detection criteria, identifying the most sensitive discriminators applicable to a given site or even season and identify the site-specific detection threshold.

A number of criteria have been investigated, falling into two categories. The first is based on detecting departures from normal stoichiometric relations. Natural changes in $\mathrm{CO}_{2}$ concentration occur because of biological, chemical or physical processes, all of which create signals in other measurable variables. For example, the biological uptake of $\mathrm{CO}_{2}$ during primary production is always accompanied by an equivalent release of oxygen, vice-versa for respiration. Such biological processes also affect nutrient concentrations. Natural changes in $\mathrm{CO}_{2}$ arising because of mixing or advection of different water masses will also be accompanied by changes in temperature and or salinity. Although definition of natural stoichiometric relationships has been based on observational data sets $[23,24]$, models of sufficient complexity can be used to extend these definitions dynamically over larger areas and longer time periods [25], as well as defining the optimal combination of variables [26].

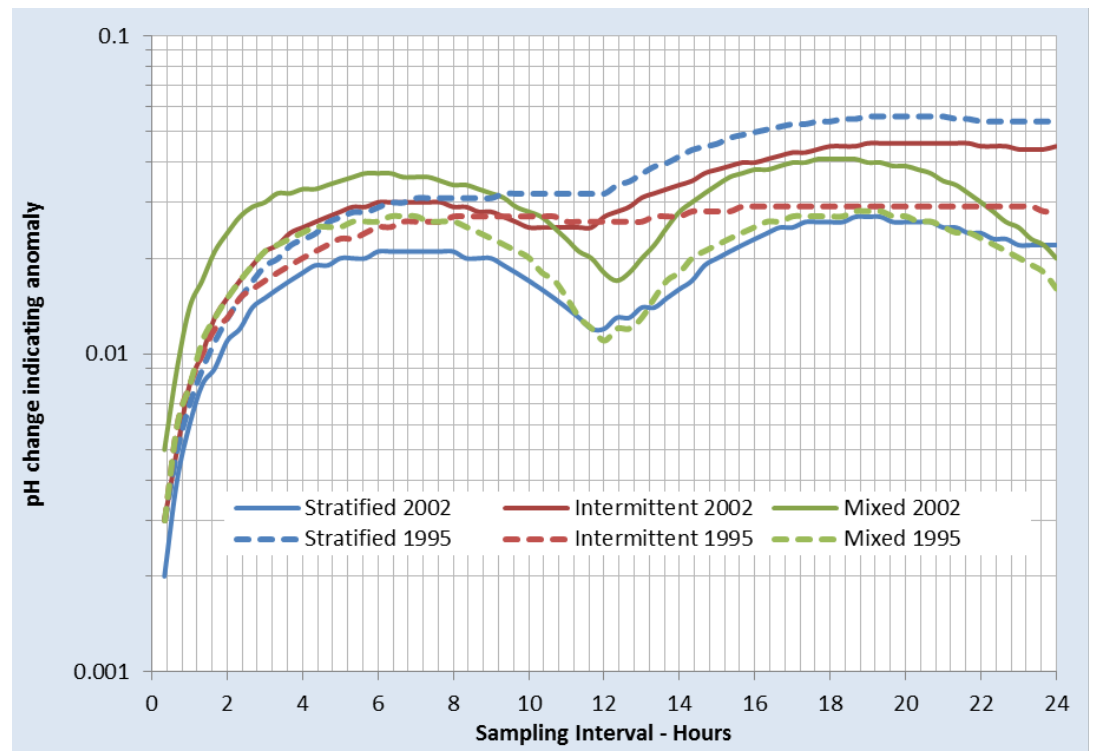

Figure 3. Theoretical anomaly detection thresholds, expressed as the rate of $\mathrm{pH}$ change relative to the sampling interval. Any rate change larger than indicated would suggest an anomaly requiring further investigation. Lines represent three different sites and two different years.

The second category utilizes the fact that given the mobility of $\mathrm{CO}_{2}$ plumes, sensors (whether fixed or themselves mobile) are likely to be exposed to fluctuations in $\mathrm{CO}_{2}$ over space and timescales that are different from the spatiotemporal gradients that result from natural processes [22,27]. By using models to define these natural 
spatiotemporal gradients it is possible to then identify gradient-based thresholds which can be used to identify anomalous signals. For example if monitoring can approach sub-hourly frequencies, which is entirely within the capability of existing platforms, then criteria as sensitive as a change of $\mathrm{pH}$ of 0.01 unit over 20 minutes or less could be a reliable indicator of a release (Fig 3).

\subsection{Optimizing sensor deployment and locating leaks}

Designing monitoring programs to detect discharges which could theoretically occur anywhere within an area of several hundred square kilometres is challenging, one must take into account the variability of the marine environment and ocean dynamics. However, even if one can distinguish between $\mathrm{CO}_{2}$ from a release from that due to natural variability, it is an additional challenge to identify the leak location. Building on knowledge of leak morphology, natural variability and anomaly criteria, models allow us to devise the most cost-efficient deployment of sensors to maximise detection. By quantifying how water movement impacts dispersion of $\mathrm{CO}_{2}$ plumes, models can determine the minimum number of sensors and their optimal locations $[28,29,30]$, or the optimal deployment pathway of Autonomous Underwater Vehicles (AUVs) to maximise the likelihood of detection using Bayesian techniques [31] (Fig 4). Research is underway to develop machine learning techniques [32], inverse methods [33] and "greedy set" algorithms [34] to further optimise survey design.
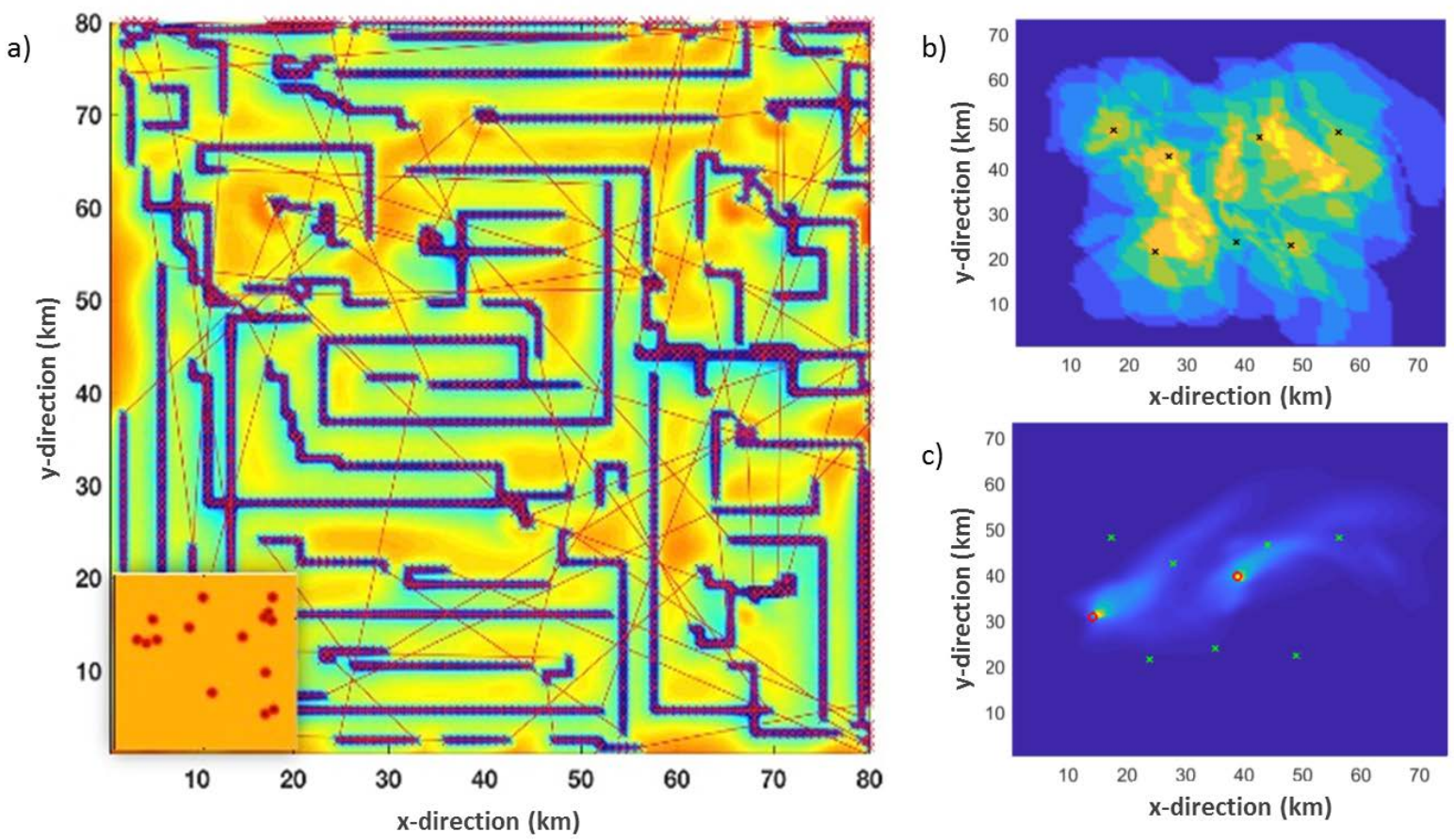

Figure 4. a) Optimal Autonomous Underwater Vehicles (AUV) route for rapid detection in an area with 15 wells (lower left corner) derived from Bayesian analysis. Measurement locations are shown in blue, AUV pathways as red lines whilst the background colour represents the probability of a leak at that location. b) Optimal sensor placements using simulation of 36 leaks at different locations with constant flow-rate and fixed detection threshold. Sensors placed such that any of 36 leaks would be detected while keeping the number of sensors minimal. c) Pseudo-colour plot of the averaged (in time) concentration c(x; t), measurement locations (crosses) and estimated leak locations (circles) using linear transport equation with sparse optimization method.

Model simulations suggest that a release event of $1 \mathrm{~T}^{\text {day }}{ }^{-1}$ may be detectable at $50 \mathrm{~m}$ distance, scaling to $5 \mathrm{~km}$ distance for a $100 \mathrm{~T}_{\text {day }}{ }^{-1}$ release, although local hydrodynamics would cause significant variability in the detection length-scale. 


\subsection{Risk assessments and communication}

Environmental risk assessments are generally required by permitting authorities [35]. If required, marine models could contribute by quantifying potential impact from hypothetical release scenarios. These can utilize either the established relation between leak rate and affected area (Fig 5) or where specific risks are identified involve more detailed model studies in which impacts to species are explicitly coded into simulation models [36]. Such models can also consider other existing or potential stressors on a particular environment, as multiple stressors are generally recognized as more than cumulatively impactful on ecosystems. Additionally the accumulation of model scenario assessments can be used to inform stakeholders, including the public, regarding risks. Studies show that the potential impact from a small CCS leak will be very local (Fig 5), and that only catastrophic scale releases are likely to have some degree of regional scale impact. Importantly risks from CCS must be contrasted with risks of not performing climate mitigation, which are likely to be global and severe.

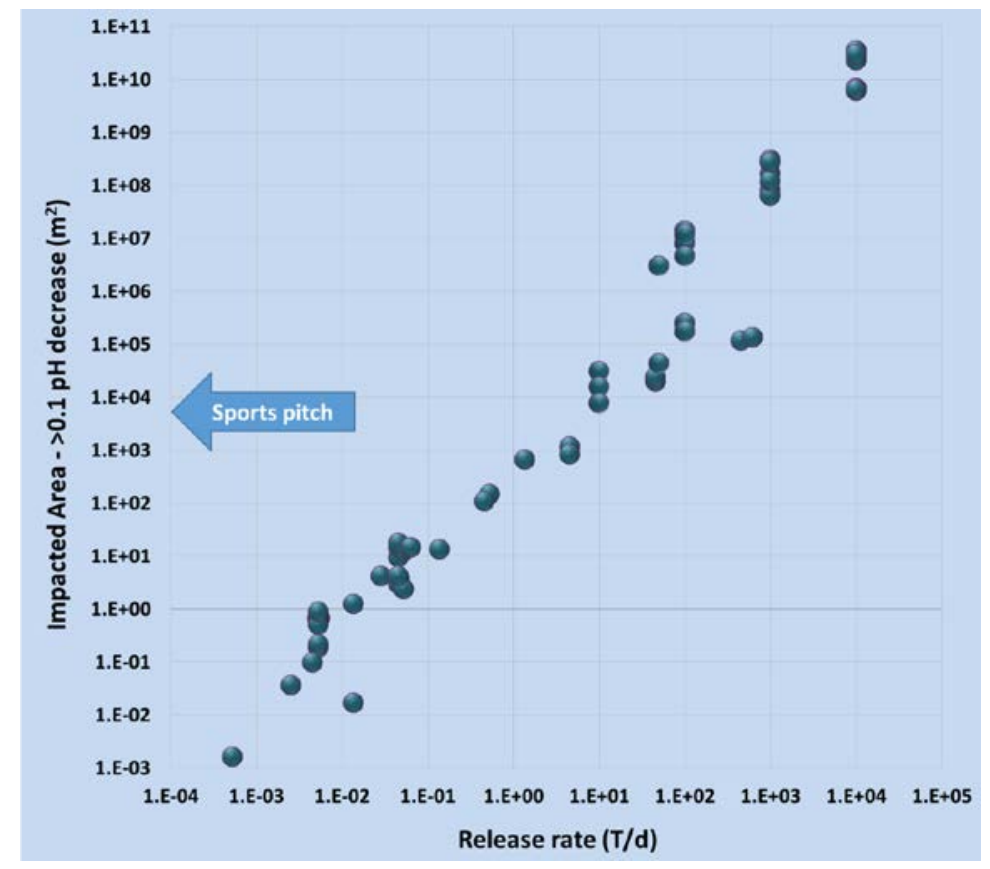

Figure 5. Model ensemble relationship between $\mathrm{CO}_{2}$ release rate and impacted area. The size of a typical sports pitch (e.g. football) is indicated as a reference point. A decrease of $0.1 \mathrm{pH}$ unit is a conservative indicator of impact potential.

\section{Translation to operational capability and further challenges}

The bad news for offshore CCS storage operations is that marine environments are so diverse that a generic definition of baselines, anomaly criteria and monitoring strategies will have little value, although the fundamental principles will be transferable from location to location. The positive outcome is that we can use models, ideally coupled with some observational data to ensure accuracy, to work out optimal criteria and strategies for individual storage sites, which will both minimise the cost of such monitoring whilst maximising rigour and thereby public acceptance.

It is the case that suitable marine models require a significant effort to develop, evaluate and interpret. They are often computationally expensive to run and models that are bespoke to particular storage sites are necessary. However, it is also the case that the majority of sites under consideration for offshore storage are already described by relevant model systems that at least resolve 3D hydrodynamics, boundary forcing and some degree of 
biogeochemistry; such systems are already used for a variety of research and operational purposes. Many model systems now explicitly model carbonate chemistry, given the research interest in ocean acidification, and new model systems with high resolution are becoming more common. There are several examples cited here where existing model systems have been adapted to address CCS challenges, and where models are not yet optimal, code transfer can generally minimise further development effort.

Using appropriately skilled models to derive baseline understanding, explore release scenarios and optimal site specific detection criteria is far more cost effective than deploying large observational programmes. However, model evaluation and quality assessment require in-situ environmental data, and establishing environmental baselines should be an intrinsic part of site characterisations. To assure adequate yet inexpensive baseline observations, early involvement of the marine modelling community is recommended, such that observational programmes can be targeted efficiently. However, there is much to gain by ensuring that national scientific monitoring programmes facilitate the monitoring required for CCS activities. Key parameters for CCS are common to those required for many other research purposes, e.g. temperature, salinity, $\mathrm{pH}, \mathrm{pCO}_{2}, \mathrm{O}_{2}$, productivity, nutrients, etc. Perhaps the harder challenge is to reduce the bias towards sea surface measurements and to increase the frequency of observations such that variability on all scales is adequately captured.

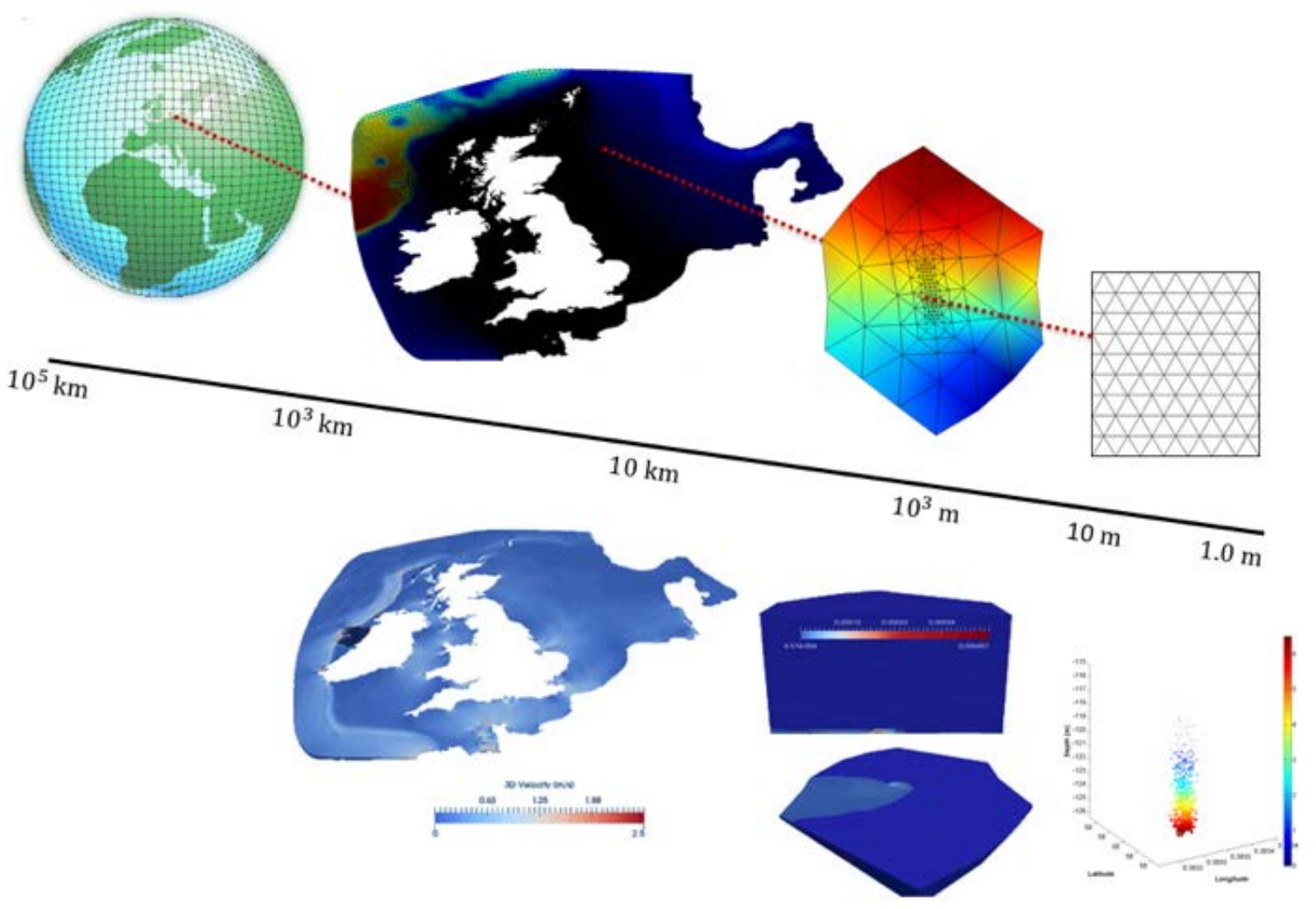

Figure 6. The multi-scale, multiphase numerical model, with forcing down from global scale data (the top left); into the shelf-seas / coastal scale (top middle shows the mesh, bottom left shows sample currents); with a nested ghost model reducing the scale to the meter scales (top left showing the mesh, bottom middle shows the flow of dissolved $\mathrm{CO}_{2}$ solution); including an example $\mathrm{CO}_{2}$ leakage plume module (bottom left, providing the dissolved solution distribution and dynamics of the bubble plume in the model). 
In terms of further model development, a number of initiatives are underway. One such (Fig 6) is aiming to combine an ability to accurately represent currents and ocean scale mixing phenomena with an ability to model the ultra-fine scale of bubble dynamics and multiphase chemistry. Other initiatives are developing an ability to simulate high-resolution leakage scenarios with concurrent simulation of natural biogeochemical processes. Whilst such models are not necessarily optimal for operational use currently, due to computational costs, they do allow for testing and hypothesis development and the production of sufficiently accurate simpler models.

Models can therefore address all aspects of the detection, confirmation/localisation and quantification processes required as part of a comprehensive monitoring system. However, models cannot completely supplant in-situ measurements, observed data will be essential for model validation and quality assessments. A symbiosis between seagoing research and theoretical modellers will be a win-win situation, providing data for model assessments and development generating further process understanding and iteratively optimising measurement programs. We argue that it is critical to ensure that observational programmes, models and their data products that are already delivered by national science programmes for a variety of uses are optimised for CCS applications, where necessary. Open source software tools that enable bespoke analysis of variability, leak morphology, monitoring strategies and impact assessment on a site-by-site basis can then be developed, providing the base data requirements are met.

\section{Acknowledgements}

This work has received funding from the European Union's Horizon 2020 research and innovation programme under grant agreement No.654462 (STEMM-CCS) and the Norwegian Research Council (CLIMIT project no 254711, BayMoDe).

\section{References}

[1] Ciavatta, S., Kay, S., Saux-Picart, S., Butenschon, M., Allen, J.I., 2016. Decadal reanalysis of biogeochemical indicator and fluxes in the North West European shelf-sea ecosystem. Journal of Geophysical Research - Oceans 121, 1824-1845. doi:10.1002/2015JC011496

[2] Holt, J., Schrum, C., Cannaby, H., Daewel, U., Allen, J.I., Artioli, Y., Bopp, L., Butenschon, M., Fach, B.A., Harle, J., Pushpadas, D., Salihoglu, B., Wakelin, S., 2016. Potential impacts of climate change on the primary production of regional seas: A comparative analysis of five European seas. Progress in Oceanography 140, 91-115. doi:10.1016/j.pocean.2015.11.004

[3] Allen, J.I., Somerfield, P.J., 2009. A multivariate approach to model skill assessment. Journal of Marine Systems 76, 83-94. doi:10.1016/j.jmarsys.2008.05.009

[4] STEMM-CSS; Strategies for Environmental Monitoring of Marine Carbon Capture and Storage, an EU Horizon 2020 funded project. http://stemm-ccs.eu

[5] BayMoDe, Bayesian Monitoring Design, A Research Council of Norway (CLIMIT program) funded project: https://www.forskningsradet.no/prosjektbanken/\#/project/NFR/254711/Sprak=en

[6] ECO2, Sub-seabed CO2 Storage: Impact on Marine Ecosystems. http://www.eco2-project.eu/

[7] Haeckel M., Blackford J., 2015. CCT2 Synthesis report on predicted impacts and uncertainties, ECO2 Deliverable D12.3, 42 p. DOI: 10.3289/ECO2_D12.3

[8] Alendal, G., Omar, A., Denny, A. R., Baumberger, T., Beaubien, S. E., Vielstädte, L., Dewar, M., Chen, B., Pedersen, R. B., De Vittor, C. and Johannessen, T. (2013) Technical synthesis report on droplet/bubble dynamics, plume dynamics and modelling parameters, use of hydro-acoustics to quantify droplet/bubble fluxes, and carbonate system variable assessment. ECO2 Deliverable, D3.1, 51 pp. DOI 10.3289/ECO2_D3.1.

[9] Dewar, M., Chen, B., Evgeniy, Y., Avlesen, H., Alendal, G., Ali, A. and Vielstädte, L., 2013. Technical report on verified and validated application of droplet/bubble plume-, geochemical- and general flow- models. ECO2 Deliverable, D3.3, 81 pp. DOI 10.3289/ECO2_D3.3.

[10] McGinnis, D. F., M. Schmidt, T. DelSontro, S. Themann, L. Rovelli, A. Reitz, and P. Linke, 2011. Discovery of a natural CO2 seep in the German North Sea: Implications for shallow dissolved gas and seep detection, J. Geophys. Res., 116, C03013, doi: 10.1029/2010JC006557.

[11] Roberts, J.J., Stalker, L., 2017. What have we learned about $\mathrm{CO}_{2}$ leakage from field injection tests? Energy Procedia 114, $5711-5731$. doi:10.1016/j.egypro.2017.03.1710

[12] Blackford, J.C., Stahl, H., Bull, J.M., Bergès, B.J.P., Cevatoglu, M., Lichtschlag, A., Connelly, D.P., James, R.H., Kita, J., Long, D., Naylor, M., Shitashima, K., Smith, D., Taylor, P., Wright, I., Akhurst, M., Chen, B., Gernon, T.M., Hauton, C., Hayashi, M., Kaieda, H., Leighton, T.G., Sato, T., Sayer, M.D.J., Suzumura, M., Tait, K., Vardy, M.E., White, P.R., Widdicombe, S., 2014. Detection and impacts 
of leakage from sub-seafloor deep geological carbon dioxide storage. Nature Climate Change 4, 1011-1016. doi:10.1038/NCLIMATE2381

[13] Blackford, J.C., Jones, N., Proctor, R., Holt, J.T., 2008. Regional scale impacts of distinct $\mathrm{CO}_{2}$ additions in the North Sea. Marine Pollution Bulletin 56, 1461-1468. doi:10.1016/j.marpolbul.2008.04.048

[14] Phelps, J.J.C., Blackford, J.C., Holt, J.T., Polton, J.A., 2015. Modelling Large-Scale $\mathrm{CO}_{2}$ Leakages in the North Sea. International Journal of Greenhouse Gas Control 38, 210-220. doi:10.1016/j.ijggc.2014.10.013

[15] Blackford, JC; Torres, R; Artioli, Y; Cazenave, P. 2013. Modelling dispersion of $\mathrm{CO}_{2}$ plumes in sea water as an aid to monitoring and understanding ecological impact. Energy Procedia 37, 3379-3386. doi:10.1016/j.egypro.2013.06.226

[16] Dewar, M., Saleem, U., Khajepor, S., Chen, B. Prediction of Greenhouse Gas Leakages from Potential North Sea Storage Sites into Coastal Waters by an Unstructured, Multi-Scale and Multi-Phase Flow Model, this issue.

[17] Dewar, M., Wei, W., McNeil, D., Chen, B., 2013. Small-scale modelling of the physiochemical impacts of $\mathrm{CO}_{2}$ leaked from sub-seabed reservoirs or pipelines within the North Sea and surrounding waters. Marine Pollution Bulletin 73, 504-515. doi:10.1016/j.marpolbul.2013.03.005

[18] Saleem, U., Dewar, M., Chen, B. Numerical Modelling of $\mathrm{CO}_{2}$ Flow through Sediments into Water Column, this issue.

[19] Elliot, A.J., Wallace, D.C., 1989. Dispersion of Surface Plumes in the Southern North Sea, Dt. Hydrogr. Z., 42, 16.

[20] Hofmann, G.E., Smith, J.E., Johnson, K.S., Send, U., Levin, L.A., Micheli ,F., Paytan, A., Price, N. N., Peterson, B., Takeshita, Y., Matson, P.G., Crook, E.D., Kroeker K.J., Gambi , M.C., Rivest, E.B., Frieder, C.A., Yu, P.C., Martz, T.R., 2011. High-Frequency Dynamics of Ocean pH: A Multi-Ecosystem Comparison. PLoS ONE 6(12), e28983. doi:10.1371/journal.pone.0028983

[21] Artioli, Y., Blackford, J.C., Butenschon, M., Holt, J.T., Wakelin, S.L., Thomas, H., Borges, A.V., Allen, J.I., 2012. The carbonate system of the NW European shelf: sensitivity and model validation. Journal of Marine Systems 102-104, 1-13. doi:10.1016/j.jmarsys.2012.04.006

[22] Blackford, J.C., Artioli, Y., Clark, J., de Mora, L., 2017. Monitoring of offshore geological carbon storage integrity: implications of natural variability in the marine system and the assessment of anomaly detection criteria. International Journal of Greenhouse Gas Control 64, 99-112. doi:10.1016/j.ijggc.2017.06.020

[23] Uchimoto, K., Nishimura, M., Kita, J., Xue, Z., 2018. Detecting $\mathrm{CO}_{2}$ leakage at offshore storage sites using the covariance between the partial pressure of $\mathrm{CO}_{2}$ and the saturation of dissolved oxygen in seawater. International Journal of Greenhouse Gas Control 72, $130-137$. doi:10.1016/j.ijggc.2018.03.020

[24] Botnen, H., Omar, A.M., Throseth, I., Johannessen, T., Alendal, G., 2015. The impact of submarine $\mathrm{CO}_{2}$ vents on seawater: implications for detection of subsea carbon sequestration leakage. Limnology and Oceanography 60, 402-410. doi:10.1002/lno.10037

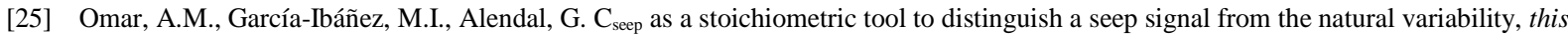
issue.

[26] Lessin, G., Artioli, Y., Bruggeman, J., Blackford, J. Can we use departure from natural co-variance relationships for monitoring of offshore carbon storage integrity? this issue.

[27] Alendal, G., Blackford, J., Chen, B., Avlesen, H., \& Omar, A., 2017. Using Bayes Theorem to Quantify and Reduce Uncertainties when Monitoring Varying Marine Environments for Indications of a Leak. Energy Procedia, 114, 3607-3612. http://doi.org/10.1016/j.egypro.2017.03.1492

[28] Greenwood, J., Craig, P., Hardman-Mountford, N., 2015. Coastal monitoring strategy for geochemical detection of fugitive $\mathrm{CO}_{2}$ seeps from the seabed. International Journal of Greenhouse Gas Control 39, 74-78. doi:10.1016/j.ijggc.2015.05.010

[29] Hvidevold, H.K., Alendal, G., Johannessen, T., Ali, A., Mannseth, T., Avlesen, H., 2015. Layout of CCS monitoring infrastructure with highest probability of detecting a footprint of a $\mathrm{CO}_{2}$ leak in a varying marine environment. International Journal of Greenhouse Gas Control 37 274-279. doi:10.1016/j.ijggc.2015.03.013

[30] Ali, A., Frøysa, H.G., Avlesen, H., Alendal, G., 2016. Simulating spatial and temporal varying $\mathrm{CO}_{2}$ signals from sources at the seafloor to help designing risk-based monitoring programs. Journal of Geophysical Research-Oceans 121(1), 745-757. doi:10.1002/2015JC011198

[31] Alendal, G. (2017). Cost efficient environmental survey paths for detecting continuous tracer discharges. Journal of Geophysical Research-Oceans, 122(7), 5458-5467. http://doi.org/10.1002/2016JC012655

[32] Gundersen, K., Oleynik, A., Alendal, G., Skaug, H.J., Avlesen, H., Berntsen, J., Blackford, J., Blaser, N., Cazenave, P. Combining models and machine learning techniques to design leak detection monitoring, this issue.

[33] Oleynik, A., Gundersen, K., Alendal, G., Skaug, H.J., Avlesen, H., Berntsen, J., Blackford, J., Blaser, N., Cazenave, P. Simplified modelling as a tool to locate and quantify fluxes from a $\mathrm{CO}_{2}$ seep to marine waters, this issue.

[34] Cazenave, P., Torres, R., Blackford, J., Artioli, Y. Regional modelling to inform the design of sub-sea $\mathrm{CO}_{2}$ storage monitoring networks, this issue.

[35] Dixon, T., McCoy, S.T., Havercroft, I., 2015. Legal and Regulatory Developments on CCS. International Journal of Greenhouse Gas Control 40, 431-448. doi:10.1016/j.ijggc.2015.05.024

[36] Lessin, G., Artioli, Y., Queirós, A.M., Widdicombe, S., Blackford, J.C., 2016. Modelling impacts and recovery in benthic communities exposed to localised high $\mathrm{CO}_{2}$. Marine Pollution Bulletin 109, 267-280. doi:10.1016/j.marpolbul.2016.05.071 